\title{
Brasil do ano 2000 revisitado: desafios em inovação tecnológica e o papel da universidade
}

\section{Revisiting Brazil in the year 2000: challenges in technological innovation and the role to be played by the university}

\section{Brasil del año 2000 revisitado: desafíos en innovación tecnológica y el papel de la universidad}

Pedro Bastos de Souza, Mestre em Direito e Políticas Públicas pela Universidade Federal do Estado do Rio de Janeiro (UniRio), pesquisador na UniRio - Grupo CNPq Direito, Democracia e Desenvolvimento, Rio de Janeiro, RJ, Brasil. E-mail: pedrobastos2@ globo.com.

\section{Resumo}

O presente estudo tem como objetivo revisar temas que estavam na ordem do dia no limiar do século XX em matéria de inovação, empreendedorismo e produção científica no Brasil, destacando o papel das universidades públicas nesse processo. Ressalta-se o papel da inovação no desenvolvimento socioeconômico e a necessidade de o Estado investir em políticas públicas na área. Debate-se em que medida houve uma evolução positiva no cenário brasileiro neste início de século $X X I$ e quais são os pontos que permanecem pendentes. Enfatizam-se as conexões entre inovação e produção de conhecimento na universidade, com base em três eixos de análise: educação básica, regionalização do ensino superior e expansão da pós-graduação.

Palavras-chave: Inovação. Produção Científica. Papel da Universidade. 


\section{Abstract}

The present study aims to revise themes that were the order of the day at the beginning of the 20th Century in relation to innovation, entrepreneurship and scientific production in Brazil, pointing out the role of the public university in the process. It notes the role of innovation in the social-economic development and the need for the State to invest in public policies in the area. We discuss the extent of the positive evolution in the Brazilian scenario at the threshold of the $21^{\text {st }}$ Century, as well as the points still pending. We emphasize the connections between innovation and knowledge production in the university, based on three analysis axes: basic education, higher education regionalization and graduate study expansion.

Keywords: Innovation. Scientific Production. University Role.

\section{Resumen}

El presente estudio tiene como objetivo revisar temas que estaban en la orden del día en el principio del siglo XX como materia de innovación, emprendimiento y producción científica en Brasil, destacando el papel de las universidades públicas en este proceso. Queda resaltado el papel de la innovación en el desenvolvimiento socioeconómico y la necesidad de la inversión del Estado en políticas públicas en el área. Discútase en que medida hubo una evolución positiva en el panorama brasileño en este inicio del siglo XXI y cuáles son los puntos que permanecen pendientes. Se enfatizan las conexiones entre innovación y producción de conocimientos en la universidad, con base en tres ejes de análisis: educación básica, regionalización de la enseñanza superior y expansión de pos graduación.

Palabras clave: Innovación. Producción Científica. Papel de la Universidad. 


\section{Introdução}

A inovação tecnológica e o investimento em produção de conhecimento representam pontos-chave na inserção de um Estado em uma sociedade global. A globalização econômica e financeira, com o encurtamento de distâncias causado pelo desenvolvimento das telecomunicações, dos meios de transporte e das tecnologias digitais, faz com que o capital se torne móvel e com que se busquem oportunidades de negócio - muitas vezes de forma predatória - nos quatro cantos do globo. O consumismo e a busca pelo efêmero são características do mundo pós-moderno.

Nesse cenário, a inovação tecnológica e a busca por novas oportunidades de lucro no mercado capitalista são atributos marcantes. Ainda que se façam críticas a esse modo de ser do mundo contemporâneo, o fato é que a globalização gera efeitos cada vez mais nefastos àqueles Estados que permanecem alheios a tal realidade. 0 investimento em Ciência e Tecnologia adquire, assim, papel geopolítico fundamental, pois amortece os efeitos negativos da globalização. Portanto, os que priorizarem a inovação terão uma melhor inserção na economia global e melhores condições de promover desenvolvimento social.

O Brasil, sétima maior economia do mundo de acordo com o Banco Mundial (2014), ocupa um lugar sui generis nesse quadro. Apresentase como país industrializado e, ao mesmo tempo, subdesenvolvido em temas como educação básica, transportes e logística, saneamento e, principalmente, distribuição de renda.

O país tem avançado em matéria de produção científica e de formação acadêmica de mestres e doutores, ocupando o $13^{\circ}$ lugar no ranking mundial, segundo relatório divulgado pela consultoria especializada Thomson Reuters (2014). No entanto, ocupa lugar apenas intermediário no que se refere a registro de patentes, indicativo da inovação tecnológica.

Em 2000, Hernan Chaimovich já apontava os principais gargalos e desafios em matéria da produção em Ciência e Tecnologia no Brasil, ressaltando a falta de uma política de regionalização e de democratização

$24^{a}$ posição, segundo a Organização Mundial de Propriedade Intelectual (2010). Conforme o Inpi, em 2012, o Brasil representou $1,6 \%$ do total de patentes produzidas no mundo. 
na produção de conhecimento, destacando a prevalência do setor público nos investimentos em pesquisa acadêmica. O autor apontou ainda as dificuldades de financiamento, embora reconhecesse, à época, que, em linhas gerais, o processo evolutivo era positivo.

O presente estudo tem como objetivo reanalisar os temas que estavam na ordem do dia no limiar do século XX em matéria de inovação e produção científica no Brasil, destacando o papel das universidades públicas nesse processo. Após apresentar breve revisão de literatura sobre o tema, faz uma resenha do artigo Brasil, Ciência, Tecnologia: alguns dilemas e desafios, publicado por Chaimovich na revista Estudos Avançados, n. 14, em 2000. Em seguida, debate em que medida houve uma evolução positiva no cenário brasileiro e que pontos permanecem pendentes, com base em três eixos de análise: educação básica, regionalização do ensino superior e expansão da pós-graduação.

\section{Breve revisão de literatura}

Conforme Pereira e Kruglianskas (2005), em uma economia sólida, a inovação tecnológica deve ser resultado de um ambiente que produz ciência de ponta e influencia direta e indiretamente o setor produtivo, especialmente por meio dos setores de pesquisa e desenvolvimento gerados no bojo das empresas. A crítica dos autores é quanto à falta de interação entre ciência e setor produtivo:

O Brasil é um país que produz ciência de fronteira, mas que não consegue interagir, em um nível adequado, com o setor produtivo. O resultado dessa baixa incorporação de tecnologia de ponta diretamente nos produtos torna-os pouco competitivos, tanto no mercado interno como no externo (PEREIRA; KRUGLIANSKAS, 2005, p. 3).

A afirmação dos autores pode ser lida com ressalvas, uma vez que, sob aspecto qualitativo, a produção de "ciência de fronteira" é algo esporádico. Conforme salientado por Leite (2004), deve-se dinamizar o processo de substituição competitiva das importações e o desenvolvimento de centros locais de tecnologia. 0 foco aqui deve ser a diminuição da dependência tecnológica. E isso só é possível mediante 
clara articulação do Estado com a iniciativa privada e universidades / centros de pesquisas, para um esforço conjunto de superação de debilidades e construção de competências.

É bom lembrar, como ressaltado por Fisher (2011), que há pelo menos cinco estratégias para incentivar a inovação tecnológica: 1) os governos se encarregam, por si próprios, de desenvolver a inovação tecnológica; 2) os governos subsidiam atividades inovadoras de atores privados; 3) os governos instituem recompensas post hoc mediante oferta de prêmios ou recompensas; 4) os governos, em alguns contextos, podem auxiliar os inovadores a impedirem que certas informações se tornem públicas mediante acordo de confidencialidade ou proibindo a engenharia reversa de produtos; 5) os governos podem conferir direitos de propriedade intelectual aos inovadores, dando-Ihes direitos exclusivos sob certos aspectos de suas inovações - direito de usar, de fabricar, de vender, de reproduzir e de preparar produtos derivados das inovações -, de forma a conceder um monopólio artificial da exploração econômica de sua inovação.

Deve-se investir na formação de profissionais com maior qualificação, especialmente na área de tecnologia. Conforme Kawasaky (1997), deseja-se formar profissionais com competência para ingressar no contexto de mercado, mas, sobretudo, profissionais críticos que percebam as "fragilidades" e as "brechas" do sistema para a criação de "nichos específicos". Citem-se, nesse sentido, áreas como Petróleo \& Gás, Tecnologia da Informação, Controle Ambiental e Transportes.

Pereira e Kruglianskas (2005) analisam o papel e os impactos da Lei n 10.973, de 2004, a chamada Lei de Inovação Tecnológica (LIT). A LIT busca promover e incentivar o desenvolvimento científico, a pesquisa e a capacitação tecnológicas de forma a viabilizar o desenvolvimento, conforme definem os arts. 218 e 219 da Constituição Federal. Os autores destacam, em especial, a sinergia para viabilização de empresas emergentes, por meio do processo de incubação, e a colaboração com empresas consolidadas. A lei também é orientada para a geração de estímulos para a participação das entidades públicas de pesquisa no processo de inovação e se preocupa em definir normas que permitam 
a transferência e o licenciamento de tecnologia das universidades e institutos de pesquisa públicos do país para o setor produtivo nacional.

Pereira e Kruglianskas (2005) advertem, contudo, que é necessário ir além da aprovação e da regulamentação de uma lei, que não se torna efetiva por si mesma. Para superar dificuldades e atingir seus propósitos, a implementação da Lei de Inovação Tecnológica exige que ocorra efetiva interação das ações governamentais com o segmento privado, a comunidade científica e tecnológica e os trabalhadores.

Ribeiro Neto (1999), por sua vez, centrou-se no impacto das inovações tecnológicas nas relações de poder no âmbito das empresas e no ambiente de trabalho. Conforme o autor, as mudanças ocorrem: no conteúdo e natureza das tarefas; nas habilidades requeridas para a consecução do trabalho; nas pressões e ritmos de trabalho; na interação entre empregados; na quantidade de mão de obra; no horário e na duração das jornadas.

Analisando o fenômeno de descentralização das universidades públicas brasileiras, Ester Luck (2004) ressalta que o diagnóstico do ensino superior no Brasil revela uma tendência de expansão acentuada do ensino privado e de diminuição da participação relativa das instituições públicas no seu desenvolvimento. Agrega-se a isto a asfixia financeira das instituições federais de ensino superior. Está cada vez mais evidente a necessidade de inovação no perfil da oferta e da formação profissional, do comprometimento com o desenvolvimento de uma sociedade mais justa.

Já o enfoque de Fiorin (2007) é voltado para a importância da internacionalização da produção científica. O que impulsiona o desenvolvimento científico e tecnológico são a cooperação e a internacionalização. Afirma o autor:

É um truísmo afirmar que o conhecimento e a inovação têm um papel significativo no desenvolvimento dos diferentes países e, portanto, na melhoria das condições de vida de suas populações. No entanto, como cada sociedade não pode reinventar a roda, é imperioso que 
haja cooperação entre suas comunidades de pesquisadores. Por isso, os diferentes países têm uma preocupação muito grande com a internacionalização da produção científica (FIORIN, 2007, p. 266).

De fato, a cooperação em nível internacional é fundamental. A interação entre modos de pensar e agir diferentes e a troca de saberes, especialmente quando realizadas em uma relação de horizontalidade, é essencial para que se evolua em matéria de produção e de conhecimento. É nesse sentido que um programa como o Ciência sem Fronteiras adquire papel estratégico.

Em relação à universidade, uma das grandes questões enfocadas por Ferreira e Leopoldi (2013) é a de definir qual o seu papel em uma sociedade baseada no conhecimento. Se, na era industrial, ela desempenhou um papel secundário, fornecendo pessoal qualificado e pesquisa básica, hoje, a universidade deve se tornar mais engajada no suporte à inovação e na liderança de políticas locais em direção a uma abordagem mais empreendedora. Ao mesmo tempo, a universidade precisa também preservar a sua orientação aberta e de longo prazo na pesquisa acadêmica.

De acordo com Calderane Oliveira (2013), a universidade deve ser a instituição núcleo da economia do conhecimento. A cooperação entre governo, universidade e empresa é elemento crucial para viabilizar o desenvolvimento científico e tecnológico exigido pela economia moderna. Essas interações entre os agentes vêm se transformando em decorrência da evolução dos sistemas de inovação.

Velho (2007) realizou estudo sobre o papel da formação de pesquisadores no sistema de inovação, apontando para o fato de que a mera existência de mestres e doutores não gera benefícios de maneira automática. É preciso que algumas condições se façam presentes. Nesse sentido, defende:

A existência de um sistema de pós-graduação que forme o número necessário de pesquisadores e que seja sustentável; que a composição das áreas de conhecimento enfatizadas pela pós-graduação seja capaz de refletir as necessidades nacionais; que a formação oferecida tenha 
qualidade e relevância para as ocupações a que se dedicarão os titulados; que haja inserção dos titulados em atividades e carreiras profissionais fora do setor acadêmico. De acordo com o argumento desenvolvido, a presença de tais condições indicaria que a pós-graduação brasileira estaria funcionando de acordo com os novos modelos interativos sobre produção e uso do conhecimento (VELHO, 2007, p. 27).

Conclui a autora que o ensino de pós-graduação brasileiro tem se expandido consideravelmente, formando contingentes crescentes de mestres e doutores, mas ainda teria de crescer muito para se equiparar aos índices praticados nos países avançados (proporção de mestres/ doutores por habitante). Aponta-se a dificuldade de manter esse nível em expansão apenas com recursos públicos, o que coloca em risco a sustentabilidade do sistema (Velho, 2007).

Conforme Jesus et al. (2009), o crescimento da importância da inovação e da propriedade intelectual no país pode ser notado diante da grande preocupação em regular leis relacionadas ao tema, bem como da a implementação de programas e políticas de apoio à inovação, de forma que o país possa atingir um patamar mais elevado em relação ao seu desenvolvimento econômico e social, gerando riquezas oriundas das tecnologias desenvolvidas pelos principais agentes empreendedores do ramo tecnológico no país (instituições de ensino e pesquisa, pequenas, médias e grandes empresas).

É importante ainda mencionar os estudos de Castells (1999), que ressaltam que a chamada revolução da tecnologia da informação altera a forma do próprio capitalismo, da produção de conhecimento e das relações sociais. 0 autor reforça o papel geopolítico estratégico do desenvolvimento e da pesquisa de novas tecnologias, especialmente em um mundo globalizado.

De acordo com o autor, as novas tecnologias de informação difundiram-se mundialmente de forma acelerada em menos de 20 anos, entre as décadas de 1970 e 1990, por meio de uma lógica que é característica da revolução tecnológica: a aplicação imediata no próprio desenvolvimento da tecnologia gerada, conectando o mundo por meio da tecnologia da informação. Nesse novo cenário, o capital torna-se 
cada vez mais móvel, e as relações de trabalho tendem a se tornar cada vez mais flexíveis. No processo, os investimentos do Estado e, em especial, das universidades exerceram - e continuam a exercer - papel fundamental para o fomento da inovação (Castells, 1999).

\section{Ponto de partida: dilemas e desafios em C\&T no ano 2000}

O presente tópico se propõe a apresentar uma resenha crítica do artigo Brasil, Ciência, Tecnologia: alguns dilemas e desafios, publicado por Hernan Chaimovich na revista Estudos Avançados, n. 14, em 2000. As questões abordadas servirão de base para uma atualização do panorama em matéria de Ciência e Tecnologia no Brasil e as relações deste campo com o papel da universidade.

Chaimovich, professor titular aposentado do Departamento de Química da USP, traça um panorama realista do estágio em que a produção de ciência e tecnologia se encontrava no final do século XX. Em sua análise, ele articula de forma crítica questões específicas afeitas à Ciência com as políticas e o papel do Estado e com as demandas por desenvolvimento econômico e social, com um enfoque que privilegia os dilemas organizacionais, em um cenário que já leva em conta o fenômeno da globalização.

Ressaltando a importância dos investimentos e programas em Ciência e Tecnologia para o desenvolvimento brasileiro, Chaimovich destaca cinco pontos dignos de nota: 1) o equilíbrio entre a liberdade do cientista e a necessidade social do conhecimento; 2) a tensão entre o prazer individual da criação e as condições objetivas da estrutura onde o cientista trabalha; 3 ) as alternativas entre a centralização de criação de C\&T e os desequilíbrios regionais; 4) as alternativas entre fontes de financiamento e desafios decorrentes entre o público e o privado; 5) a relação entre Ciência, Tecnologia e Inovação.

A relação de essencialidade entre a evolução da ciência e sua aplicação no mundo desenvolvido é destacada por Chaimovich, que toma como exemplo os Estados Unidos, onde o poder público investiu 
pesado em C\&T, especialmente na indústria bélica e aeroespacial. 0 chamado “poder de compra” do Estado espraiou-se por outros setores, expandindo a pesquisa em todas as direções do conhecimento.

É interessante notar que, mesmo em economias capitalistas em alto grau, como nos EUA, o Estado exerceu e continua a exercer papel determinante no fomento do desenvolvimento científico-tecnológico, em que pesem os novos ventos neoliberais e globalizantes. No Brasil, o desenvolvimento tecnológico e a ciência básica relacionada com as tecnologias também podem ser determinados pelas decisões políticas do Estado de investir no setor.

Chaimovich (2000) destaca, em mais de um momento do artigo, a importância de não se restringir os horizontes de pesquisa somente àquelas áreas/pesquisadores que tenham altíssimo potencial de sucesso. Ao contrário, o autor ressalta a necessidade de se expandir investimentos em todas as áreas da ciência, ainda que, por vezes, sejam privilegiadas as chamadas áreas de fronteira. Em outra passagem, alerta o autor para o fato de que o financiamento de pesquisadores avulsos (balcão) apenas para projetos com muita probabilidade de sucesso "traz o risco de se diminuir o componente central da criação em ciência que é a procura pelo realmente desconhecido" (CHAIMOVICH, 2000, p. 139, grifo nosso).

Pode-se fazer uma breve metáfora com a situação do Brasil nos esportes olímpicos. De um lado, há a estratégia de investir, em curto prazo, em atletas de alto rendimento que já possuem um potencial de resultados positivos. Obtêm-se, assim, bons resultados em contextos pontuais e em esportes específicos. É o que fazem Quênia e Jamaica no atletismo. De outro lado, há a estratégia de pensar o desenvolvimento esportivo em longo prazo, fomentando a formação na base e estimulando uma cultura esportiva multifacetada, de modo massificado. É o que fazem as grandes potências olímpicas, como EUA, China e Rússia.

Em todo caso, reconhece-se a evolução do Brasil no campo da ciência, embora a entrada excessivamente tardia do país no processo de produção organizada prejudique a produção nacional. Chaimovich 
(2000) destaca tal fato e lembra que a proporção de produção brasileira indexada no Institute for Scientific Information (ISI) ${ }^{2}$ passou de $0,4 \%$ em 1990 para mais de 1,2\% em 2000. 0 motivo para tal aumento não seria devido à evolução do Produto Nacional Bruto por habitante (PNB/hab), uma vez que o crescimento econômico do Brasil foi pequeno no período - pífio até, se comparado a outros países da América do Sul. O motivo principal estaria no próprio aumento dos investimentos estatais em ciência e na pós-graduação.

Mesmo considerando o avanço positivo, o autor enfatiza a excessiva concentração da produção científica nas universidades públicas brasileiras, que, no fim do século XX, vinham crescendo na pósgraduação, mas não na graduação. Por um lado, tal dado é positivo, pois ajuda a desconstruir a imagem de senso comum de que o serviço público é falido e ineficiente. Por outro, demonstra a inanição e a paralisia do setor educacional privado na área de pesquisa. Nesse sentido, segundo Chaimovich (2000, p. 137), "a expansão do ensino superior, que hoje alcança a mais de dois milhões de habitantes, dá-se especialmente num sistema privado que pouco contribui para a produção nacional de ciência e tecnologia”. Preocupavam o autor, à época, a sustentabilidade e o potencial de crescimento desse fenômeno.

Chaimovich (2000), ainda que demonstrando a vital importância do papel da ciência para o desenvolvimento, alerta para o fato de que o sistema de C\&T, por si só, não determina o desenvolvimento. É necessária uma relação de intercâmbio e constante interface com o sistema nacional de inovação, com a incorporação de valor a produtos de exportação e com a solução de problemas como a distribuição de renda e o acesso à saúde.

É ressaltado que a fonte de financiamento mais significativa de sistemas de ciência é pública em todo o mundo. A ciência básica é desenvolvida quase inteiramente em universidades e institutos de pesquisa. O financiamento deve ser harmônico, cobrindo todas as áreas. Conforme frisa Chaimovich (2000), “a decisão política sobre esta linha de financiamento é uma decorrência da compreensão, em nível de Estado,
${ }^{2}$ Trata-se de um sistema de organização de informação científica que coleta títulos e resumos de trabalhos publicados em revistas de circulação nacional. 
da correlação entre a produção de ciência básica e os outros sistemas que conduzem ao desenvolvimento socialmente justo".

O investimento em ciência deve ser planejado e deve haver uma conciliação entre a vontade individual do cientista (balcão) e a necessidade de investimento em áreas prioritárias/programas. 0 julgamento pela qualidade é o denominador comum entre ambos. Em vez de investir apenas em projetos com muita probabilidade de sucesso ou em áreas já exitosas, deve-se priorizar áreas da ciência que, por serem pouco desenvolvidas, constituem um empecilho ao desenvolvimento da própria ciência, enfatizando-se a interdisciplinaridade.

No contexto da universidade pública, Chaimovich não somente advoga pelo aumento de vagas que acompanhe o crescimento de concluintes do ensino médio, mas também alerta para o fato de que tal expansão, sem aumento do quadro docente e da infraestrutura, pode desestruturar a produção científica no país.

Outro alvo de críticas do autor é o modelo excessivamente centrado nas universidades de pesquisa. Ele lembra que em outros países há a coexistências desse modelo com outros tipos de instituição, como cursos técnicos e estabelecimentos profissionais, além de cursos de menor duração³.

Em síntese, de acordo com Chaimovich (2000, p. 139),

[...] dificilmente as universidades públicas vão sobreviver como produtoras de conhecimento se o sistema de ensino superior não se diferenciar, se a matrícula não se expandir e se não houver pesados investimentos em pessoal e infraestrutura.

3 Na verdade os cursos de menor duração, ora chamados de pósmédio, ora de graduação tecnológica, foram transpostos para o Brasil pelas instituições privadas com um viés ainda mais distanciado da atividade de pesquisa do que a própria universidade privada tradicional.
Questão central abordada por Chaimovich (2000) diz respeito à necessidade premente de reduzir a disparidade regional na produção de 
conhecimento no Brasil. Mostrando a excessiva concentração de projetos na região Sudeste, o autor clama por um papel mais ativo do Estado, com a criação de universidades públicas de qualidade em áreas mais carentes. A interiorização e a distribuição mais equilibrada do ensino público superior tendem a trazer ganhos para o desenvolvimento em C\&T e, principalmente, funcionam como polo catalisador do desenvolvimento social e econômico, contribuindo para a redução das desigualdades regionais.

O processo de expansão regional depende, contudo, não só de um aumento quantitativo de instituições de ensino, mas também de uma adequada estrutura e de investimentos na qualidade acadêmica, levando em consideração as realidades locais e contando com a participação da comunidade científica na formatação dos projetos e na formulação de prioridades.

O quinto e último ponto apontado pelo autor é a necessária integração entre ciência básica, tecnologia e inovação, que depende do produto de uma forma única. É a cadeia produtiva, e não o conhecimento, que determina a opção do investimento público em tecnologia e inovação. A universidade deve participar ativamente desse processo.

É possivel observar nas palavras de Chaimovich (2000) um espírito pragmático no sentido de solucionar gargalos - aumento de vagas, desconcentração da produção de conhecimento, modelos alternativos à universidade de pesquisa. É possível perceber também algumas posições políticas claras que dizem respeito a questões estruturais em matéria de C\&T: o uso social do conhecimento, o papel fundamental do Estado, as relações múltiplas com os sistemas produtivos e a participação necessária da academia nas decisões.

Chaimovich procura ancorar sua análise em dados e estatísticas referentes, por exemplo, à proporção de concluintes do ensino médio, à expansão do número de matrículas no ensino privado e à concentração regional na produção de C\&T. Passados cerca de 15 anos da publicação de seu trabalho, torna-se interessante realizar uma pesquisa para atualizar os dados, além de revisitar algumas questões levantadas pelo 
autor, checando como se deu a expansão da universidade pública e da produção científica no Brasil no período. É o que se passa a fazer no tópico a seguir.

\section{Revisando o tema: evoluções e desafios que continuam}

\section{A questão da educação básica}

Embora o país apresente números de uma economia de grande porte e um grande potencial como mercado consumidor, algumas questões fundamentais permanecem sem solução adequada. Entre elas, devem ser citados primordialmente os índices em matéria de educação básica. Não se entra aqui no mérito de aspectos qualitativos da educação básica, mas, apenas pelos dados quantitativos disponíveis do Pnud, já é possível mensurar a dificuldade de formação de futuros profissionais em nível universitário e a dificuldade de se massificar ações inovadoras em Ciência e Tecnologia, num país em que a evasão escolar no ensino fundamental chega a $24,3 \%$.

Segundo dados do Pnud (2009) referentes a 2007, o Brasil ocupava a $67^{a}$ posição no Índice de Educação, componente do Índice de Desenvolvimento Humano (IDH) e que leva em conta uma média ponderada entre as taxas de alfabetização e escolarização nos ensinos primário, secundário e superior. Há uma demanda não suprida em relação à mão de obra de nível técnico (ensino pós-médio ou profissionalizante) para áreas tecnológicas. Nesse sentido, devem ser canalizados maiores investimentos dos entes públicos para a formação desses profissionais.

No âmbito da educação básica e levando em conta o universo da América do Sul, o Brasil ocupa o último lugar quanto à média de anos de escolaridade $(7,2)$ e o penúltimo lugar em taxa de alfabetização $(90,3 \%)$, perdendo apenas para o Peru. Além disso, menos de 50\% da população concluiu o ensino médio. Nesse ponto, o país perde para diversos países, estando em sexto lugar no ranking, conforme se pode observar na tabela a seguir: 
Tabela 1. Educação nos países da América do Sul

\begin{tabular}{|c|c|c|c|c|c|c|}
\hline País & $\begin{array}{c}\text { Média de } \\
\text { anos de } \\
\text { escolaridade }\end{array}$ & $\begin{array}{c}\text { Expectativa } \\
\text { de anos de } \\
\text { escolaridade }\end{array}$ & $\begin{array}{c}\text { Adultos } \\
\text { alfabetizados } \\
\text { (> 15 anos) }\end{array}$ & $\begin{array}{c}\text { População } \\
\text { com ensino } \\
\text { médio ou } \\
\text { mais (> 25 } \\
\text { anos) }\end{array}$ & $\begin{array}{c}\text { Satisfação } \\
\text { com a } \\
\text { qualidade } \\
\text { de ensino }\end{array}$ & $\begin{array}{c}\text { Evasão } \\
\text { escolar } \\
\text { no ensino } \\
\text { fundamental }\end{array}$ \\
\hline Chile & 9,7 & 14,7 & $98,6 \%$ & $74 \%$ & $44 \%$ & $2,6 \%$ \\
\hline Argentina & 9,3 & 16,1 & $97,8 \%$ & $56 \%$ & $62,6 \%$ & $6,2 \%$ \\
\hline Bolívia & 9,2 & 13,5 & $91,2 \%$ & $44,5 \%$ & $57,9 \%$ & $5,9 \%$ \\
\hline Peru & 8,7 & 13,2 & $89,6 \%$ & $52,9 \%$ & $49,1 \%$ & $N / D$ \\
\hline Guiana & 8,5 & 10,3 & $N / D$ & $55,6 \%$ & $\mathrm{~N} / \mathrm{D}$ & $16,5 \%$ \\
\hline Uruguai & 8,5 & 15,5 & $98,1 \%$ & $49,8 \%$ & $55,8 \%$ & $4,8 \%$ \\
\hline Paraguai & 7,7 & 12,1 & $93,9 \%$ & $36,9 \%$ & $66,9 \%$ & $21,9 \%$ \\
\hline Equador & 7,6 & 13,7 & $91,9 \%$ & $36,6 \%$ & $74,5 \%$ & $19,4 \%$ \\
\hline Venezuela & 7,6 & 14,4 & $95,5 \%$ & $52,4 \%$ & $81,2 \%$ & $7,9 \%$ \\
\hline Colômbia & 7,3 & 13,6 & $93,4 \%$ & $43,1 \%$ & $71,7 \%$ & $1,5 \%$ \\
\hline Suriname & 7,2 & 12,4 & $94,7 \%$ & $43,7 \%$ & $\mathrm{~N} / \mathrm{D}$ & $9,7 \%$ \\
\hline BRASIL & 7,2 & 14,2 & $90,3 \%$ & $49,5 \%$ & $53,7 \%$ & $24,3 \%$ \\
\hline
\end{tabular}

Fonte: Pnud/ONU 2013. Publicada em O Globo, 14/3/2013.

A alta taxa de evasão ainda no ensino fundamental permite antever que os demais índices não avançaram muito nos últimos anos. Há um grande funil separando estratos da população em relação aos niveis de escolaridade. Por mais que haja um aumento contínuo de ingressantes em nivel superior, permanece um deficit de qualificação no ensino médio, o que impacta em formação profissional ou mesmo em escassez de mão de obra em profissões de nível técnico.

Dados da OCDE e do Banco Mundial (2008), tratados por Kerstenetzky e Alvarenga (2009), indicam que o Brasil, no que se refere à educação, é o país que destina a menor quantidade de recursos (da totalidade de países de que se tem informação, só fica atrás da Argentina, do Uruguai e da Jordânia em termos de gasto per capita), assumindo a $54^{\mathrm{a}}$ posição, em 2006, no ranking de desempenho em ciências do Programa para Avaliação Internacional dos Estudantes (PISA), que reúne 57 países. Segundo os dados apresentados, o gasto per capita do Brasil com seus estudantes é de menos de um terço do que o da Coreia do Sul. Já o Japão, por exemplo, investe, per capita, mais do que o quíntuplo do Brasil. 
Kerstenetzky e Alvarenga (2009) afirmam ainda que "no universo pesquisado o Brasil pode ser identificado como o país que destina a menor quantidade de recursos à educação para todos os niveis escolares estudados [grifo das autoras]". As autoras derrubam dois mitos: o de que não se gasta pouco, mas se gasta mal; e o de que haveria ganho econômico-financeiro em substituir o financiamento público pelo privado:

[...] nosso exercício não comprovou o adágio de que "não gastamos pouco, gastamos mal", pelo menos no que se refere à oferta pública de oportunidades educacionais. Nossas contas mostram claramente que sob diversas perspectivas gastamos pouco. O que não quer dizer que gastamos bem esse pouco. Porém, a evidência do baixo gasto é acachapante; o "mal" que alegadamente haveria no financiamento público do ensino superior, se cancelado nem de longe cobriria o menor dos déficits por nós estimados, já que esse financiamento corresponde a 0,9\% do PIB (KERSTENETZKY; ALVARENGA, 2009, p. 8).

\section{A regionalização do ensino universitário e a pesquisa em C\&T}

Se, por um lado, o pouco volume geral de gastos pode ser tido como desanimador, a lógica de redistribuição, por meio de um processo de regionalização, tem sido bem-sucedida.

O Estado brasileiro tem adotado como política prioritária um processo de regionalização e interiorização das instituições de ensino superior, seja pela criação de campi avançados no interior, seja pela criação de novas estruturas, que seguem duas lógicas: instalações em regiões pobres, carentes de desenvolvimento econômico, e instalação em municípios que são importantes centros regionais em determinadas mesorregiões geográficas.

Este processo ganha fôlego ainda na primeira gestão do governo Lula. Somente entre 2003 e 2006, o país ganhou 14 novas universidades públicas, totalizando 49 campi, todos localizados em cidades do interior (AGÊNCIA CÂMARA, 2013). 
Um exemplo de política pública de interiorização da atividade universitária que vem sendo desenvolvido ao longo de mais de uma década é o da Universidade Federal Fluminense, que possui campi em dezenas de municípios do interior fluminense. Cite-se a presença da instituição em municípios da Baixada Fluminense, Macaé, Rio das Ostras, Campos, Angra dos Reis e Volta Redonda, entre outros (LUCK, 2004).

Conforme a política estabelecida pelo MEC (2010), o processo de expansão da rede de instituições federais de ensino baseia-se nas seguintes premissas, que levam em conta dimensões sociais, geográficas e de desenvolvimento:

\section{Tabela 2. Dimensões da expansão das IES Federais}

\begin{tabular}{|c|c|c|}
\hline Dimensão Social & Dimensão Geográfica & $\begin{array}{c}\text { Dimensão de } \\
\text { Desenvolvimento }\end{array}$ \\
\hline $\begin{array}{l}\text { 1) Universalização } \\
\text { de atendimento } \\
\text { aos Territórios da } \\
\text { Cidadania; } \\
\text { 2) Atendimento aos } \\
\text { municípios populosos } \\
\text { e com baixa receita per } \\
\text { capita, integrantes do } \\
\text { G100; } \\
\text { 3) Municípios com } \\
\text { percentual elevado de } \\
\text { extrema pobreza. }\end{array}$ & $\begin{array}{l}\text { 1) Atendimento } \\
\text { prioritário aos } \\
\text { municípios com mais } \\
\text { de } 50.000 \text { habitantes } \\
\text { ou microrregiões não } \\
\text { atendidas; } \\
\text { 2) Universalização } \\
\text { do atendimento } \\
\text { às mesorregiões } \\
\text { brasileiras; } \\
\text { 3) Municípios em } \\
\text { microrregiões não } \\
\text { atendidas por escolas } \\
\text { federais; } \\
\text { 4) Interiorização da oferta } \\
\text { pública de Educação } \\
\text { Profissional e Ensino } \\
\text { Superior; } \\
\text { 5) Oferta de Educação } \\
\text { Superior Federal por } \\
\text { estado abaixo da } \\
\text { média nacional. }\end{array}$ & $\begin{array}{l}\text { 1) Municípios com } \\
\text { Arranjos Produtivos } \\
\text { Locais (APLs) } \\
\text { identificados; } \\
\text { 2) Entorno de grandes } \\
\text { investimentos. }\end{array}$ \\
\hline
\end{tabular}

Fonte: Portal MEC (2013)

Entre 2002 e 2010, o número de campide universidades federais passou de 148 para 274 (MEC, 2013). O número de municípios atendidos, por sua vez, passou de 230 para 275. Além disso, novas instituições criadas já são formatadas de modo a possuírem mais de um campus, 
aumentando seu espectro de atuação em determinada micro ou mesorregião. Apenas a título de exemplo, convém citar a Universidade Federal do Sul e Sudeste do Pará, a Universidade Federal da Região do Cariri, a Universidade Federal do Oeste da Bahia e a Universidade Federal do Sul da Bahia.

Conforme Paulo Corbucci, em entrevista ao Ipea (2010), além do fenômeno da interiorização, outro ponto a se observar na dinâmica do ensino superior é que houve uma desaceleração do crescimento das instituições privadas:

Até 2003, houve um boom de criação de cursos superiores e escolas privadas. 0 setor vinha crescendo a taxas anuais entre $11 \%$ e $17 \%$. Nos últimos três anos, houve inversão nessa tendência: as taxas de crescimento são decrescentes e bem mais modestas (4,6\% em 2008). Houve uma desaceleração.

Como já apontara Chaimovich em 2000, as instituições superiores privadas, salvo honrosas exceções, continuam negligenciando quase que por completo a área de pesquisa. Focam o ensino, com um intuito de oferecer um serviço que visa apenas à satisfação imediata do cliente: inserir-se no mercado de trabalho o mais rápido possivel com a conclusão de um curso de nível superior, tratando a educação como um produto de consumo. Uma instituição de ensino superior chega a propagandear na televisão que, ao se matricular, o aluno recebe grátis "um tablet, com todo o material didático incluído" [grifo nosso]. E, nesse cenário, tanto a pesquisa como a extensão continuam majoritariamente no campo público.

Na verdade, a universidade pública, não obstante a vinculação à estrutura estatal, tem desenvolvido um grau de autonomia organizacional e independência científica considerável, que lhe permite atuar no campo de pesquisa e inovação sem ter de se submeter a interesses imediatos de grandes empresas ou de financiadores privados. 
É preciso reconhecer que tem havido uma evolução no que tange à qualificação profissional do brasileiro em relação ao número de mestres e doutores. Conforme dados compilados pelo MEC (2010), com base em informações do IBGE e da Capes, o índice de doutores titulados no país (por 100 mil habitantes) passou de 3,91 em 2002, para 5,94 em 2009. Já em relação aos mestrados acadêmico e profissional, o índice de mestres titulados no Brasil passou de 13,86 em 2002 para 20,26 em 2009.

Para esta pesquisa não foi possível acessar os dados atualizados do ISI mencionados por Chaimovich em 2000, o que seria interessante para se fazer uma análise comparativa. Dados de 2005 indicam que o patamar chegou a 1,8\% dos periódicos do ISI (FIORIN, 2007).

Em todo caso, outras fontes permitem observar uma evolução positiva em matéria de produção científica. Segundo dados do Ministério da Ciência, Tecnologia e Inovação (2013), o Brasil ocupa o $13^{\circ}$ lugar no ranking dos países com maior volume de produção científica do mundo. Entre 2007 e 2008, o Brasil aumentou em 56\% o número de artigos publicados em revistas internacionais especializadas.

Ainda segundo informação do MCT (2013), a taxa de crescimento na elaboração de trabalhos científicos é de $8 \%$ ao ano, enquanto a média mundial está em $2 \%$. No Brasil, a produção científica concentra maior fatia nas áreas de pesquisas agrícolas e ciências naturais.

Além disso, o Brasil tem buscado inserir-se no mundo globalizado por meio de projetos como o Ciência sem Fronteiras, com o envio de estudantes para alguns dos principais polos de produção de conhecimento no mundo. As chamadas "ciências duras" são tidas como prioritárias no programa.

Em que pese se ressaltar a extrema importância do investimento em pesquisa na área de Ciências Exatas e Biológicas, a inclusão das Ciências Sociais no programa decerto traria um salto de qualidade à produção acadêmica brasileira. 
Ressalte-se que há um movimento em sentido inverso, que faz parte do fortalecimento do papel geopolítico do Brasil nas relações Sul-Sul. O Brasil tem recebido bolsistas de pós-graduação oriundos, sobretudo, da Colômbia, do Peru, de países do Mercosul e da África Iusófona, por meio do programa PEC-PG, do CNPq. Em 2011, por exemplo, foram aprovados 126 bolsistas de doutorado pelo programa. Cite-se, ainda, o Acordo entre o CNPq e a Academia de Ciências para os Países em Desenvolvimento (The World Academy of Sciences - TWAS), para a realização de doutorado e pós-doutorado no Brasil na área de Ciências Naturais.

Na experiência de internacionalização da universidade brasileira, mencione-se igualmente a Universidade da Integração Internacional da Lusofonia Afro-Brasileira (Unilab), criada pela Lei n 12.289/2010. Trata-se de uma instituição federal de ensino, de natureza autárquica, com campus principal no município de Redenção, na região do Maciço do Baturité, no Ceará. Além dos objetivos corriqueiros de uma instituição superior de ensino federal (ensino, pesquisa e extensão), a Unilab tem como missão específica formar recursos humanos para contribuir com a integração entre o Brasil e os demais países da Comunidade dos Países de Língua Portuguesa (CPLP), especialmente os países africanos, bem como promover o desenvolvimento regional e o intercâmbio cultural, científico e educacional (art. $2^{\circ}$ da Lei $n^{\circ}$ 12.289/10). Somente em 2012, foram selecionados 170 estudantes oriundos da África lusófona e do Timor-Leste. Em 2014, foram 364 vagas.

Outro viés da política de integração luso-afro-brasileira da Unilab é a celebração de termos de cooperação com instituições de ensino e pesquisa no âmbito da CPLP e também com a China, por conta da Região Administrativa Especial (RAE) de Macau, que mantém o português como idioma oficial. Foram celebrados convênios com todos os membros do bloco, visando, em linhas gerais, ao intercâmbio de docentes e discentes, à realização de pesquisas e eventos em conjunto, à realização de treinamentos e à prestação de consultorias. 
Apesar dos avanços, ressalte-se, como o faz Fiorin (2007), que há um descompasso entre a produção científica e a aplicação tecnológica do conhecimento mensurada pelo número de patentes registradas. O Brasil não tem avançado no seu registro, permanecendo na $24^{\mathrm{a}}$ posição mundial da lista dos países que mais registram patentes. Outra ressalva é a de que, como também destacou o autor, se considerarmos o peso da economia brasileira no mundo e o número de habitantes do país, verifica-se que ainda é baixa a participação do Brasil na produção científica mundial.

É relevante o aumento quantitativo da produção, mas, ainda assim, esta permanece baixa em uma análise per capita. É preciso continuar o aumento quantitativo, mas, concomitantemente, melhorar a qualidade da produção. São, assim, dois os desafios: seguir com o aumento da produção e melhorar sua qualidade. O que se observa é que há uma expansão quantitativa do número de mestres e doutores, mas os investimentos per capita continuam baixos. Assim, como bem lembrou Velho (2007), o número de bolsas de pesquisa não acompanha o crescimento do número de ingressantes. Nos anos 1990, por exemplo, era muito mais fácil conseguir uma bolsa de pesquisa do que em 2014.

\section{Considerações finais}

Em relação ao ano 2000, base do estudo de Chaimovich, a produção científica brasileira avançou de modo positivo, aumentando o número de publicações em nível internacional, bem como a quantidade de mestres e doutores. Se quantitativamente o Brasil forma mestres e doutores quase na mesma marca de países como a França e a Inglaterra, o fato é que tal número ainda é pequeno se comparado com o total da população. Além disso, em termos de qualidade de produção, o Brasil fica aquém em relação a esses países.

Contudo, o aumento da base de mestres e doutores não é acompanhado de um aumento do investimento público per capita em educação, que é significativamente inferior ao de países como Chile e México. Isso, de certa forma, é reflexo das desigualdades no país. 
Aliadas a tal fato, a prevalência de altos índices de evasão escolar e a baixa média de anos de estudos da população (a menor da América do Sul) fazem com que seja difícil, em curto ou médio prazo, vislumbrar um cenário em que o país ocupe um lugar de ponta em matéria de inovação e excelência em Ciência e Tecnologia, muito embora já seja o $13^{\circ}$ colocado no ranking em matéria de produção científica mundial.

Há, assim, forte contradição entre o desempenho não satisfatório em educação básica e os avanços (predominantemente quantitativos) em nivel de pós-graduação. Tal contradição reflete, na verdade, a perversa pirâmide social brasileira e a concentração de renda.

Com a globalização, as oportunidades surgem justamente para os que ocupam o topo dessa pirâmide e podem qualificar-se profissional e academicamente. A base da pirâmide, contudo, fica à margem das benesses da globalização, uma vez que não consegue sequer concluir o ensino fundamental. Políticas de inclusão social e ações afirmativas no âmbito da educação superior tendem, em médio prazo, a melhorar esse quadro.

As estratégias de desenvolvimento econômico e de pesquisa em inovação devem levar em conta essa realidade, para que o processo se dê de modo sustentado em longo prazo e possa se caracterizar como verdadeiramente inclusivo. Além disso, a melhoria na educação básica decerto trará uma evolução qualitativa na produção científica.

O movimento de descentralização na produção de conhecimento, por meio da interiorização de universidades públicas e sua instalação em áreas de baixo desenvolvimento socioeconômico, representa uma ação afirmativa no sentido dessa inclusão, por meio da democratização do acesso ao ensino superior e da criação de oportunidades de negócio nessas áreas. Nesse ponto, a universidade pública funciona como dinamizadora da vida regional, não só na qualificação de mão de obra, mas também no pioneirismo em inovação.

O intercâmbio com países produtores de ciência de ponta, por meio do programa Ciência sem Fronteiras, também é um passo 
importante, embora se deva reconhecer a importância de investir também em um programa semelhante que contemple igualmente as ciências humanas e sociais.

Recebido em 06/05/2015 Aprovado em 03/07/2015

\section{Referências}

AGÊNCIA CÂMARA - Câmara dos Deputados. MEC destaca interiorização das universidades públicas, Brasília, DF, 20 jun. 2013. Disponível em: <www.camara.leg.br>. Acesso em: $1^{\circ}$ mar. 2015.

\section{CALDERAN, L. L.; OLIVEIRA, L. G. A inovação e a interação Universidade -} Empresa: uma revisão teórica. Centro de Estudos Avançados de Governo e de Administração Pública, Laboratório de Análise de Políticas Públicas do CEAG/UnB. Brasília, 2013. (Série Textos de Discussão CEAG/UnB).

CHAIMOVICH, H. Brasil, Ciência, Tecnologia: alguns dilemas e desafios. Estudos Avançados, n. 14, 2000.

FERREIRA, A.; LEOPOLDI, M. A. A contribuição da universidade pública para a inovação e o desenvolvimento regional: a percepção de gestores e pesquisadores. Revista GUAL, Florianópolis, v. 6, n. 1, p. 60-82, jan. 2013.

FIORIN, J. L. Internacionalização da produção científica: a publicação de trabalhos de Ciências Humanas e Sociais em periódicos internacionais. RBPG, Brasília, v. 4, n. 8, p. 263-281, dez. 2007.

FISHER, W. W. Intellectual Property and Innovation: Theoretical, Empirical, and Historical Perspectives. Industrial Property, Innovation, and the Knowledge-based Economy. Beleidsstudies Technologie Economie, v. 37, 2001.

JESUS, D. S. de et al. Disseminação da cultura de inovação e propriedade intelectual no contexto dos ensinos médio e técnico em uma instituição de ensino. In: CONGRESSO INTERNACIONAL EM INOVAÇÃO E GESTÃO (ICIM), 5., 2009, São Paulo. Anais... PUC-SP, dez. 2009. 
IPEA - Instituto de Pesquisa Econômica Aplicada. Expansão para o interior - Governo inicia processo de descentralização do ensino superior. Desafios do desenvolvimento, n. 10, ano 7, ed. 58, 26 fev. 2010. Disponível em: <www.desafios.ipea.gov.br>. Acesso em: 10 abr. 2015.

KAWASAKI, C. S. Universidades Públicas e Sociedade: uma parceria necessária. Rev. Fac. Educ., São Paulo, v. 23, n. 1-2, jan./dez. 1997

KERSTENETZKY, C. L.; ALVARENGA, L. V. B H. Déficit de educação no Brasil: uma estimativa. Centro de Estudos sobre Desigualdade e Desenvolvimento (CEDE), Universidade Federal Fluminense, Rio de Janeiro, 2009. (Texto para Discussão n. 16).

LEITE, A. D. A Economia Brasileira: de onde viemos e para onde vamos. Rio de Janeiro: Editora Campus/ Elsevier, 2004.

LUCK, E. H. A interiorização na Universidade Federal Fluminense: uma vocação e um desafio. In: COLÓQUIO INTERNACIONAL SOBRE GESTÃO UNIVERSITÁRIA NA AMÉRICA DO SUL, 4, 2004, Florianópolis. Anais... Florianópolis, SC, 2004.

MCT - Ministério da Ciência e Tecnologia e Inovação. Brasil e Portugal promovem encontro sobre inovação e tecnologia. Disponível em: <www. mct.gov.br>. Acesso em: 18 mar. 2015.

MEC - Ministério da Educação. Portal MEC. Expansão da Educação Superior e Tecnológica. Disponível em: <www.portal.mec.gov.br>. Acesso em: $1^{\circ}$ abr. 2015.

PEREIRA, J. M.; KRUGLIANSKAS, I. Gestão de Inovação: a Lei de Inovação Tecnológica como ferramenta de apoio às políticas industrial e tecnológica no Brasil. FGV-SP. RAE- eletrônica, São Paulo, v. 4, n. 2, jul./ dez. 2005.

PNUD - Programa das Nações Unidas para o Desenvolvimento. Organização das Nações Unidas. Atlas do Desenvolvimento Humano no Brasil. 2012. 
RIBEIRO NETO, L. G. O impacto da tecnologia de informação nas organizações: uma visão política. Revista Univ. Alfenas, n. 5, p. 95-101, 1999.

VELHO, L. O papel da formação de pesquisadores no sistema de inovação.

Cienc. Cult., São Paulo, v. 59, n. 4, 2007. 